\title{
Comparison of different anthropometric measures in the adult population in Serbia as indicators of obesity: data from the National Health Survey 2013
}

\author{
Miloš Ž Maksimović ${ }^{1, *}$, Jelena M Gudelj Rakić ${ }^{2}$, Hristina D Vlajinac ${ }^{3}$, Nadja D Vasiljević ${ }^{\text {, }}$ \\ Marina I Nikić ${ }^{4}$ and Jelena M Marinković ${ }^{5}$ \\ ${ }^{1}$ Institute of Hygiene and Medical Ecology, Faculty of Medicine, University of Belgrade, 2 Pasterova Street, \\ 11000 Belgrade, Serbia: ${ }^{2}$ Institute of Public Health of Serbia 'Dr Milan Jovanović Batut', Belgrade, Serbia: ${ }^{3}$ Institute \\ of Epidemiology, Faculty of Medicine, University of Belgrade, Belgrade, Serbia: ${ }^{4}$ Faculty of Sport and Physical \\ Education, University of Belgrade, Belgrade, Serbia: ${ }^{5}$ Institute of Medical Statistics and Informatics, Faculty of \\ Medicine, University of Belgrade, Belgrade, Serbia
}

Submitted 17 June 2015: Final revision received 7 December 2015: Accepted 15 January 2016: First published online 11 February 2016

\begin{abstract}
Objective: The present study aimed to compare different indicators of obesity in the Serbian adult population.

Design: Cross-sectional study. A stratified, two-stage, national-representative random sampling approach was used for the selection of the survey sample. Data sources were questionnaires created according to the European Health Interview Survey questionnaire. Measurements of weight, height and waist circumference (WC) were performed using standard procedures. Anthropometric measures included BMI, WC and waist-to-height ratio (WHtR).

Setting: Data for the study were obtained from the 2013 National Health Survey, performed in line with the EUROSTAT recommendations for performance of the European Health Interview Survey.

Subjects: Adults aged $\geq 20$ years.

Results: According to BMI, out of the whole studied population (12 460 adults of both sexes) $2 \cdot 4 \%$ were underweight, $36 \cdot 4 \%$ overweight and $22.4 \%$ obese. Using WC and WHtR as measures of adiposity showed that $22.5 \%$ and $42.8 \%$ of participants were overweight and $39.8 \%$ and $25.3 \%$ were obese, respectively. Men and women differed significantly in all variables observed. Overweight was more frequent in men and obesity in women regardless of adiposity measure used.

Conclusions: In spite of strong correlations between BMI, WC and WHtR, substantial discrepancies between these three measures in the assessment of overweight and obesity were found, especially in some age groups. Which of these anthropometric measures should be used, or whether two or all three of them should be applied, depends on their associations with cardiovascular or some other disease of interest.
\end{abstract}

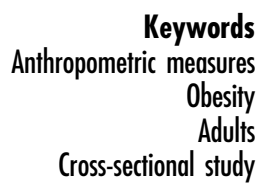

Overweight and obesity are increasing in prevalence, representing a growing public health problem worldwide. According to WHO estimates, more than $50 \%$ of the adult population in the WHO European Region is overweight and more than $20 \%$ is clinically obese ${ }^{(1)}$. Data from the National Health Survey in 2013 show that $56 \cdot 3 \%$ of the adult population in Serbia ( $\geq 20$ years old) is overweight, subdivided as $35.1 \%$ pre-obese $\left(B M I=25 \cdot 0-29.9 \mathrm{~kg} / \mathrm{m}^{2}\right)$ and $21.2 \%$ obese $\left(B M I \geq 30 \cdot 0 \mathrm{~kg} / \mathrm{m}^{2}\right)^{(2)}$. Obesity, and in particular abdominal obesity, predisposes people to a series of risk factors for chronic non-communicable diseases. It is often associated with conditions such as dyslipidaemia, arterial hypertension, insulin resistance and diabetes, which contribute to the occurrence of cardio- and cerebrovascular events ${ }^{(3,4)}$. These chronic non-communicable diseases account for the highest burden of disease in Serbia ${ }^{(5)}$.

Different anthropometric methods are used for the assessment of excess body fat. BMI is an index widely used to diagnose obesity and to identify patients at increased risk of adiposity-related adverse health outcomes. Guidelines generally suggest that those within the 
normal range of BMI do not need to lose weight, so normal-weight individuals sometimes pay little or no attention to their diet and other lifestyle habits. However, BMI does not distinguish between lean and fat mass accumulation $^{(6,7)}$ and data from a number of studies indicate that BMI often provides a false diagnosis of body fatness ${ }^{(7,8)}$. The importance of the distribution of body fat in determining health risks of obesity was suggested more than half a century ago and gained convincing evidence in the early $1990 s^{(9)}$.

Indices of abdominal obesity are better discriminators of cardiometabolic risk factors than BMI, as shown by many studies $^{(10,11)}$. Waist circumference (WC) is an alternative to BMI for indicating not only obesity risk but also obesityrelated disease risk ${ }^{(12-14)}$, and when coupled with BMI predicts health risk better than BMI alone ${ }^{(15)}$. It is used to determine centralized distribution of adipose tissue, but there are differences in body composition between different age groups and races which makes it difficult to define universal cut-off points ${ }^{(16)}$. Waist-to-height ratio (WHtR) is another proxy of central obesity that corrects WC for the height of an individual since WC may over- or underestimate risk for tall or short individuals with similar $\mathrm{WC}^{(16)}$. As shown in several studies, WHtR may identify metabolic risk among individuals defined as healthy according to BMI or $\mathrm{WC}^{(17,18)}$

So far, studies have not yet been conducted in Serbia to compare anthropometric measures in the determination of obesity. Therefore the aim of the present study was to compare different indicators of obesity in the Serbian adult population.

\section{Methods}

\section{Study population}

Data for the present study were obtained from the 2013 National Health Survey that was carried out by the Ministry of Health of Serbia and the Institute of Public Health of Serbia 'Dr Milan Jovanovic Batut'. The study population included adults aged $\geq 20$ years, permanent residents of the Republic of Serbia. Exclusion criteria were age $<20$ years, persons who lived in collective households and/or institutions, residents of Kosovo and Metohia region (under the UN Mission) and persons who were mentally unable to participate in the survey. Participants with missing data for the required variables were not included in the data analysis.

\section{Sampling design}

The National Health Survey 2013 was performed in line with the EUROSTAT recommendations for performance of the European Health Interview Survey (EHIS wave 2 methodological manual) ${ }^{(19)}$. A stratified, two-stage, national-representative random sampling approach was used for the selection of the survey sample. The 2011
Serbian Population Census framework was used for the selection of clusters. Census enumeration areas were defined as primary sampling units and were selected from each of the sampling domains by using systematic probability-proportional-to-size sampling procedures, based on the estimated sizes of the enumeration areas from the 2011 census. The first stage of sampling was completed by selecting the required number of enumeration areas from each of the four regions, from urban and rural areas separately. Four regions were identified in the sample as main strata: Vojvodina, Belgrade, Sumadija and West Serbia, and East and South Serbia. By further division on urban/rural areas a total of eight strata were obtained.

A total of 670 census enumeration areas within each region with probability proportional to size were selected during the first stage. Since the sample frame (2011 census) was not up to date, household lists in all the selected enumeration areas were updated prior to selection of households. Households were selected using a simple random sampling without replacement. The number of households selected in each selected enumeration area was ten, plus three backup households. Backup households were interviewed only if some of the first ten households were not found. If a household refused to be interviewed, a backup household was not contacted. A sample of 6700 households was selected and the household response rate was $64.4 \%$. All members of the chosen households aged $\geq 20$ years were included. Out of 12606 adults $\geq 20$ years old in the selected households, 12460 were interviewed, which yielded a response rate of $98.8 \%$.

\section{Instruments and variables}

Data sources were questionnaires created according to the European Health Interview Survey questionnaire (EHIS questionnaire $)^{(20)}$. Three questionnaires were used: one was a self-administered questionnaire for the population above 15 years of age; the other two, a questionnaire for subjects above 15 years of age and a household questionnaire, were filled by the interviewers. Variables included sociodemographic characteristics (age, sex, region, education, marital status, employment status, type of settlement) and objective findings (weight, height, WC). Participants' age was categorized into three groups: 20-44, 45-64 and $\geq 65$ years. Marital status was defined in two categories: married/living with partner and living without partner (including unmarried, divorced or widowed); and type of settlement also in two categories (urban and rural). Educational level was defined in three categories: primary or lower ( $\leq 8$ years), secondary or middle (9-12 years) and post-secondary or high ( $>12$ years, including university and post-university education). Survey participants were divided into three groups according to employment status: employed, inactive (i.e. economically inactive: students, disabled persons, pensioners, housewives) and unemployed. 


\section{Measurements}

Measurements of weight, height and WC were performed using standard procedures described elsewhere ${ }^{(21)}$. BMI was calculated by dividing body weight by height squared $\left(\mathrm{kg} / \mathrm{m}^{2}\right)$ and categorized according to the WHO criteria: $\mathrm{BMI}<18.50 \mathrm{~kg} / \mathrm{m}^{2}$ was considered as underweight, $\mathrm{BMI}=18.50-24.99 \mathrm{~kg} / \mathrm{m}^{2}$ as normal weight, $\mathrm{BMI}=25 \cdot 00-29 \cdot 99 \mathrm{~kg} / \mathrm{m}^{2}$ as overweight and $\mathrm{BMI} \geq 30 \cdot 00$ $\mathrm{kg} / \mathrm{m}^{2}$ as obesity ${ }^{(21)}$. Abdominal obesity was determined according to WC values. Participants were divided into three groups according to WC value: (i) $\leq 94 \mathrm{~cm}$ for men and $\leq 80 \mathrm{~cm}$ for women; (ii) $94.1-101.9 \mathrm{~cm}$ for men and $80 \cdot 1-87 \cdot 9 \mathrm{~cm}$ for women, considered as overweight; and (iii) $\geq 102 \mathrm{~cm}$ for men and $\geq 88 \mathrm{~cm}$ for women, considered as obese ${ }^{(12,22)}$. WHtR was calculated as WC $(\mathrm{cm})$ divided by height $(\mathrm{cm})$. The cut-off point of WHtR for discriminating associated risk in a number of different populations is set at 0.5 for both sexes and different ethnic groups ${ }^{(16,23)}$. WHtR groups were created with the following corresponding value ranges: (i) $\leq 0 \cdot 40$; (ii) $0.41-0.50$; (iii) $0.51-0.60$; and (iv) $\geq 0.61$, which represent underweight, normal weight, overweight and obese, respectively ${ }^{(11)}$.

\section{Etbical approval}

Approval for the study was obtained from the ethical review boards of all participating institutions: Institute of Public Health of Serbia and Faculty of Medicine, University of Belgrade. All respondents were informed about the purpose of the study and gave written consent to participate.

\section{Statistical analysis}

Statistical analyses were carried out on 12460 participants who had data on BMI. Continuous variables were described with means and standard deviations, categorical variables with frequencies and percentages. Prevalence rates with appropriate $95 \%$ confidence intervals were estimated for the core study outcomes, namely six categories of BMI, three categories of WC and four categories of WHtR, according to BMI, separately for male and female participants. All reported age-adjusted estimates and their 95\% confidence intervals were weighted using probabilitysampling weights calculated to reflect the underlying population of inhabitants in the Republic of Serbia in 2013. Variance estimates and confidence intervals reported account for the impact on precision of stratification and sampling weights, using Taylor-series linearization techniques for complex samples. The $\chi^{2}$ test, Student's $t$ test, the Mann-Whitney $U$ test, and one-way ANOVA or ANCOVA with post hoc Bonferroni tests were used where appropriate. Pearson's linear correlation coefficient and linear regression analysis were applied in order to analyse the relationships between BMI, WC and WHtR.

All statistical analyses were performed using the statistical software packages IBM SPSS Statistics Version 21.0 and STATA version $11 \cdot 1$, with the complex sampling design taken into account. Statistical significance was set at twosided $P<0 \cdot 05$.

\section{Results}

The study population comprised 12460 participants, 6007 (48.2\%) men and 6453 (51.8\%) women with a mean age of 48.8 years (Table 1 ). Participants were more frequently from urban areas $(60 \cdot 2 \%)$, with middle formal education (57.5\%) and married or living with a partner (65.2\%). Out of them $37.2 \%$ were employed, $29.0 \%$ were inactive and $33 \cdot 8 \%$ were unemployed. According to BMI, $2 \cdot 4 \%$ were underweight, $36.4 \%$ overweight and $22.4 \%$ obese. When WC and WHtR were used as the measures of adiposity, $22.5 \%$ and $42.8 \%$ respectively were overweight, and $39.8 \%$ and $25.3 \%$ respectively were obese. Men and women differed significantly in all variables observed. Overweight was more frequent in men and obesity in women regardless of adiposity measure used (BMI, WC or WHtR; Table 1).

Height, weight, WC and WHtR according to BMI categories are presented in Table 2 for men and in Table 3 for women. Higher means of age were observed for higher BMI categories. The same was true for mean values of weight, WC and WHtR.

Correlations between BMI, WC and WHtR were strong (Fig. 1). However, of those who were overweight and obese according to WC, $19.6 \%$ and $3.0 \%$ of men respectively and $56.3 \%$ and $12.2 \%$ of women respectively were in the group with normal BMI. Among those who were overweight and obese according to WHtR, 27.4\% and $1.0 \%$ of men respectively and $34.8 \%$ and $4.0 \%$ of women respectively were in the group with normal BMI. Also, $30.7 \%$ of men with $\mathrm{WC} \leq 94 \mathrm{~cm}$ and $20.4 \%$ with WHtR of $0.41-0.50$, as well as $9.3 \%$ of women with WC $\leq 80 \mathrm{~cm}$ and $13.2 \%$ with WHtR of $0.41-0 \cdot 50$, were overweight according to BMI (Tables 2 and 3).

Discrepancies between BMI, WC and WHtR in the assessment of overweight and obesity were also evident when the age-specific prevalence of adiposity was evaluated (Fig. 2).

\section{Discussion}

Given the public health importance of overweight and obesity and their associated health risks, recent research emphasizes the importance of developing methods and criteria to establish an accurate diagnosis ${ }^{(24)}$. Therefore there is growing interest in the investigation of different anthropometric and body shape measures to detect general and abdominal obesity. In the present study, in spite of strong correlations between BMI, WC and WHtR, substantial discrepancies between these three measures in the assessment of overweight and obesity were found, especially in some age groups. When BMI and WHtR were 
Table 1 Demographic and anthropometric characteristics, by sex, among adults ( $n$ 12460) aged $\geq 20$ years, Republic of Serbia, 2013

\begin{tabular}{|c|c|c|c|c|c|c|c|}
\hline \multirow[b]{2}{*}{ Characteristic } & \multicolumn{2}{|c|}{ All $(n 12460)$} & \multicolumn{2}{|c|}{ Men ( $n$ 6007; 48.2\%) } & \multicolumn{2}{|c|}{ Women ( $n$ 6453; $51.8 \%$ ) } & \multirow[b]{2}{*}{$P^{*}$} \\
\hline & Mean or $n$ & SD or $\%$ & Mean or $n$ & SD or $\%$ & Mean or $n$ & SD or $\%$ & \\
\hline $\begin{array}{l}\text { Age (years), mean and SD } \\
\text { Settlement, } n \text { and \% }\end{array}$ & $48 \cdot 8$ & $17 \cdot 00$ & $47 \cdot 9$ & $16 \cdot 70$ & $49 \cdot 6$ & $17 \cdot 20$ & $\begin{array}{r}<0.001 \\
0.001\end{array}$ \\
\hline Urban & 7497 & $60 \cdot 2$ & 3527 & $58 \cdot 7$ & 3970 & 61.5 & \\
\hline Rural & 4963 & 39.8 & 2480 & 41.3 & 2483 & 38.5 & \\
\hline Education, $n$ and $\%$ & & & & & & & $<0.001$ \\
\hline Low & 3070 & $24 \cdot 6$ & 1110 & 18.5 & 1960 & $30 \cdot 4$ & \\
\hline Middle & 7161 & 57.5 & 3815 & 63.5 & 3346 & 51.9 & \\
\hline High & 2230 & $17 \cdot 9$ & 1083 & $18 \cdot 0$ & 1147 & $17 \cdot 8$ & \\
\hline Marital status, $n$ and $\%$ & & & & & & & $<0.001$ \\
\hline Married/living with partner & 8123 & $65 \cdot 2$ & 4045 & $67 \cdot 3$ & 4078 & 63.2 & \\
\hline Living without partnert & 4338 & $34 \cdot 8$ & 1963 & $32 \cdot 7$ & 2375 & $36 \cdot 8$ & \\
\hline Employment status, $n$ and \% & & & & & & & $<0.001$ \\
\hline Employed & 4640 & $37 \cdot 2$ & 2720 & $45 \cdot 3$ & 1920 & 29.8 & \\
\hline Inactiveł & 3612 & $29 \cdot 0$ & 1724 & $28 \cdot 7$ & 1888 & $29 \cdot 3$ & \\
\hline Unemployed & 4208 & 33.8 & 1563 & $26 \cdot 0$ & 2946 & 41.0 & \\
\hline Height $(\mathrm{cm})$, mean and SD & $170 \cdot 1$ & 10.51 & $177 \cdot 4$ & $8 \cdot 10$ & $163 \cdot 3$ & 7.47 & $<0.001$ \\
\hline Weight $(\mathrm{kg})$, mean and SD & $77 \cdot 1$ & $16 \cdot 35$ & 84.6 & $15 \cdot 00$ & $70 \cdot 0$ & $14 \cdot 29$ & $<0.001$ \\
\hline BMI $\left(\mathrm{kg} / \mathrm{m}^{2}\right)$, mean and SD & $26 \cdot 6$ & 5.02 & 26.9 & 4.33 & $26 \cdot 4$ & 5.58 & $<0.001$ \\
\hline BMI category, $n$ and $\%$ & & & & & & & $<0.001$ \\
\hline$<18.50 \mathrm{~kg} / \mathrm{m}^{2}$ & 298 & $2 \cdot 4$ & 66 & $1 \cdot 1$ & 232 & 3.6 & \\
\hline $18.50-24.99 \mathrm{~kg} / \mathrm{m}^{2}$ & 4882 & 38.7 & 2047 & $34 \cdot 1$ & 2775 & 43.0 & \\
\hline $25.00-29.99 \mathrm{~kg} / \mathrm{m}^{2}$ & 4540 & $36 \cdot 4$ & 2604 & 43.3 & 1936 & 31.1 & $<0.001$ \\
\hline$>30.00 \mathrm{~kg} / \mathrm{m}^{2}$ & 2792 & $22 \cdot 4$ & 1285 & 21.6 & 1506 & 24.6 & $<0.001$ \\
\hline$W \bar{C}(\mathrm{~cm})$, mean and SD & 92.50 & 14.41 & $97 \cdot 24$ & 12.48 & 88.74 & 14.88 & $<0.001$ \\
\hline WC group, $n$ and $\%$ & & & & & & & $<0.001$ \\
\hline$\leq 94 \mathrm{~cm}$ for men, $\leq 80 \mathrm{~cm}$ for women & 4634 & 37.6 & 2575 & 43.2 & 2059 & 32.4 & \\
\hline $94.1-101.9 \mathrm{~cm}$ for men, $80.0-87.9 \mathrm{~cm}$ for women & 2773 & 22.5 & 1523 & $25 \cdot 6$ & 1250 & $19 \cdot 7$ & \\
\hline$\geq 102 \mathrm{~cm}$ for men, $\geq 88 \mathrm{~cm}$ for women & 4907 & 39.8 & 1858 & 31.2 & 3049 & 48.0 & \\
\hline WH'tR, mean and SD & 0.547 & 0.087 & 0.549 & 0.073 & 0.545 & 0.099 & $\begin{array}{r}0.016 \\
<0.001\end{array}$ \\
\hline $\begin{array}{l}\text { WHtR group, } n \text { and } \% \\
\leq 0.40\end{array}$ & 337 & 2.7 & 57 & 1.0 & 280 & 4.4 & \\
\hline $0.41-0.50$ & 3588 & $29 \cdot 1$ & 1519 & 25.5 & 2069 & 32.5 & \\
\hline $0.51-0.60$ & 5277 & $42 \cdot 8$ & 3049 & $51 \cdot 2$ & 2228 & 35.0 & \\
\hline$\geq 0.61$ & 3114 & $25 \cdot 3$ & 1332 & 22.4 & 1782 & $28 \cdot 0$ & \\
\hline
\end{tabular}

WC, waist circumference; WHtR, waist-to-height ratio

${ }^{*}$ According to the $X^{2}$ test, Student's $t$ test or the Mann-Whitney $U$ test, where appropriate.

†Unmarried, divorced or widowed.

†Economically inactive (students, disabled persons, pensioners, housewives).

used as measures, in both sexes the prevalence of overweight and obesity was similar in those aged $<60$ years. In older individuals the prevalence of obesity was higher when expressed by WHtR than by BMI. There are suggestions that in older people ( $\geq 60$ years) BMI is not a proper indicator of obesity ${ }^{(25)}$. In both sexes the prevalence of overweight was the lowest and the prevalence of obesity was the highest when assessed by WC. We did not try other cut-offs for WC, but it might be that its cut-offs should be reconsidered.

BMI is the most widely used indicator of obesity worldwide. According to BMI values, in our study $58.8 \%$ of adults aged $\geq 20$ years were overweight and $22 \cdot 3 \%$ were generally obese. But BMI has limitations in estimating obesity for some individuals and does not reflect fat distribution in the body ${ }^{(6,7)}$. Moreover, different studies have proved increased health risks associated with central obesity $^{(13,15)}$, consequently resulting in the development of various methods for measuring central adiposity ${ }^{(26)}$.

WC is generally recommended as the most informative index for abdominal fat distribution and is widely used.
We found that mean WC increased with the increase of BMI in both men and women as was found in other surveys ${ }^{(27,28)}$.

Our results show that central type of obesity determined by WC was verified in $31.2 \%$ of men and $48.0 \%$ of women in Serbia. Results from the study of $\mathrm{Fu}$ et al. in a Chinese population suggest that $22.2 \%$ of men and $28.1 \%$ of women were generally obese with $65.99 \%$ of men and $65.97 \%$ of women having central obesity ${ }^{(29)}$. Among those within the normal range according to BMI there are persons with the incorrect distribution of fat. In the present study, out of those who were overweight and obese according to WC, $19 \cdot 6 \%$ and $3.0 \%$ respectively, in men, and $56.3 \%$ and $12.2 \%$ respectively, in women, were in the group with normal BMI. Also, 30.7\% among men with WC $\leq 94 \mathrm{~cm}$ and $9.3 \%$ among women with $\mathrm{WC} \leq 80.0 \mathrm{~cm}$ were overweight according to BMI. Krakauer and Krakauer found that cut-offs for large WC are relevant only in the overweight BMI category, while in the category of $\mathrm{BMI}<25.0 \mathrm{~kg} / \mathrm{m}^{2}$ over $90 \%$ were under the cut-off and $90 \%$ of those with BMI above $30.0 \mathrm{~kg} / \mathrm{m}^{2}$ were above the cut-off $^{(30)}$. In a Brazilian study $32 \%$ of women had WC 
Table 2 Height, weight, WC and WHtR according to BMI category adjusted for age among men ( $n$ 6007) aged $\geq 20$ years, Republic of Serbia, 2013

\begin{tabular}{|c|c|c|c|c|c|c|c|c|c|c|c|c|c|}
\hline \multirow[b]{3}{*}{ Characteristic } & \multicolumn{12}{|c|}{ BMI category } & \multirow[b]{3}{*}{$P^{*}$} \\
\hline & \multicolumn{2}{|c|}{$\begin{array}{c}<18.50 \mathrm{~kg} / \mathrm{m}^{2} \\
(n 66)\end{array}$} & \multicolumn{2}{|c|}{$\begin{array}{c}18.50-24.99 \mathrm{~kg} / \mathrm{m}^{2} \\
(n 2047)\end{array}$} & \multicolumn{2}{|c|}{$\begin{array}{c}25.00-29.99 \mathrm{~kg} / \mathrm{m}^{2} \\
(n 2608)\end{array}$} & \multicolumn{2}{|c|}{$\begin{array}{c}30.00-34.99 \mathrm{~kg} / \mathrm{m}^{2} \\
(n 1029)\end{array}$} & \multicolumn{2}{|c|}{$\begin{array}{c}35.00-39.99 \mathrm{~kg} / \mathrm{m}^{2} \\
(n 214)\end{array}$} & \multicolumn{2}{|c|}{$\begin{array}{c}\geq 40.00 \mathrm{~kg} / \mathrm{m}^{2} \\
(n 44)\end{array}$} & \\
\hline & $\%$ or Mean & $\begin{array}{l}95 \% \mathrm{Cl}, \mathrm{SD} \\
\quad \text { or SE }\end{array}$ & $\%$ or Mean & $\begin{array}{l}95 \% \mathrm{Cl}, \mathrm{SD} \\
\quad \text { or SE }\end{array}$ & $\%$ or Mean & $\begin{array}{l}95 \% \mathrm{Cl}, \mathrm{SD} \\
\quad \text { or SE }\end{array}$ & $\%$ or Mean & $\begin{array}{l}95 \% \mathrm{Cl}, \mathrm{SD} \\
\quad \text { or SE }\end{array}$ & $\%$ or Mean & $\begin{array}{l}95 \% \mathrm{Cl}, \mathrm{SD} \\
\quad \text { or SE }\end{array}$ & $\%$ or Mean & $\begin{array}{l}95 \% \mathrm{Cl}, \mathrm{SD} \\
\text { or SE }\end{array}$ & \\
\hline$\%$ in $\mathrm{BMI}$ category and $95 \% \mathrm{Cl}$ & $1 \cdot 1$ & $0.8,1 \cdot 3$ & $34 \cdot 0$ & $32 \cdot 8,35 \cdot 2$ & $43 \cdot 3$ & $42 \cdot 1,44 \cdot 6$ & $17 \cdot 3$ & $16 \cdot 3,18 \cdot 2$ & $3 \cdot 6$ & $3 \cdot 1,4 \cdot 0$ & 0.7 & $0.5,0.9$ & $<0.001$ \\
\hline Age (years), mean and SD & $41 \cdot 26$ & $17 \cdot 67$ & 44.83 & $18 \cdot 28$ & 48.62 & $15 \cdot 92$ & 51.65 & 14.73 & 52.48 & $14 \cdot 38$ & 51.07 & 12.53 & $<0.001$ \\
\hline Height $(\mathrm{cm})$, mean and SE & $176 \cdot 4$ & 0.905 & $176 \cdot 9$ & 0.162 & $177 \cdot 3$ & 0.143 & 176.5 & 0.228 & 175.4 & 0.499 & $174 \cdot 6$ & $1 \cdot 108$ & $<0.001$ \\
\hline Weight (kg), mean and SE & $54 \cdot 2$ & 1.045 & 71.1 & 0.188 & $86 \cdot 0$ & 0.165 & 99.5 & 0.263 & $112 \cdot 9$ & 0.577 & 129.9 & 1.297 & $<0.001$ \\
\hline WC $(\mathrm{cm})$, mean and SE & $77 \cdot 8$ & 1.038 & 87.9 & 0.186 & $98 \cdot 4$ & 0.164 & 108.5 & 0.260 & $118 \cdot 4$ & 0.568 & $130 \cdot 6$ & $1 \cdot 261$ & $<0.001$ \\
\hline $\begin{array}{l}\text { WC group, \% and } 95 \% \mathrm{Cl} \\
\leq 94 \mathrm{~cm}\end{array}$ & $2 \cdot 4$ & $2 \cdot 0,2 \cdot 8$ & 65.6 & $64 \cdot 1,67 \cdot 1$ & $30 \cdot 7$ & $28 \cdot 8,32.5$ & 1.3 & $0.0,2 \cdot 6$ & 0.1 & $0.0,0.8$ & 0.1 & 0.0 .0 .3 & $<0.001$ \\
\hline $94.1-101.9 \mathrm{~cm}$ & 0.1 & $0.0,0.7$ & $19 \cdot 6$ & $17 \cdot 7,21 \cdot 6$ & 68.1 & $65 \cdot 7,70 \cdot 5$ & 11.6 & $9 \cdot 9,13 \cdot 3$ & 0.5 & $0.0,1.4$ & 0.1 & $0.0,0.5$ & \\
\hline$\geq 102 \mathrm{~cm}$ & 0.1 & $0.0,0.5$ & 3.0 & $1 \cdot 3,4.8$ & $40 \cdot 6$ & $38 \cdot 5,42 \cdot 7$ & 43.2 & $41 \cdot 7,44 \cdot 7$ & $10 \cdot 9$ & $10 \cdot 0,11 \cdot 7$ & $2 \cdot 3$ & $1.9,2 \cdot 7$ & \\
\hline WH'tR, mean and SE & 0.44 & 0.006 & 0.49 & 0.001 & 0.55 & 0.001 & 0.61 & 0.001 & 0.67 & 0.003 & 0.74 & 0.007 & $\begin{array}{l}<0.001 \\
<0.001\end{array}$ \\
\hline$\leq 0.40$ & 19.5 & $16 \cdot 9,22 \cdot 1$ & 81.9 & $71 \cdot 6,92 \cdot 1$ & 0.8 & $0.0,12 \cdot 9$ & 0.1 & $0.0,7 \cdot 2$ & 0.0 & $0.0,4 \cdot 1$ & 0.0 & $0.0,2 \cdot 0$ & \\
\hline $0.41-0.50$ & 3.6 & $3 \cdot 0,4 \cdot 1$ & $77 \cdot 0$ & $74.9,79.1$ & 20.4 & $17 \cdot 9,22 \cdot 8$ & 0.1 & $0.0,1.3$ & 0.0 & $0.0,0.6$ & 0.0 & $0.0,0.3$ & \\
\hline $0.51-0.60$ & 0.1 & $0.0,0.4$ & 27.4 & $26 \cdot 0,28 \cdot 8$ & 60.4 & $58.8,62 \cdot 0$ & 11.5 & $10 \cdot 3,12 \cdot 7$ & 0.5 & $0.0,1.2$ & 0.1 & $0.0,0.4$ & \\
\hline$>0.61$ & 0.1 & $0.0,0.4$ & 1.0 & $0.0,3.1$ & $32 \cdot 1$ & $29.6,34.6$ & $49 \cdot 3$ & $47 \cdot 5,51 \cdot 1$ & 14.5 & $13 \cdot 6,15.5$ & 3.2 & $2.7,3.6$ & \\
\hline
\end{tabular}

WC, waist circumference; WHtR, waist-to-height ratio.

${ }^{*}$ According to the $x^{2}$ test or ANOVA/ANCOVA where appropriate. 
Table 3 Height, weight, WC and WHtR according to BMI category adjusted for age among women ( $n$ 6453) aged $\geq 20$ years, Republic of Serbia, 2013

\begin{tabular}{|c|c|c|c|c|c|c|c|c|c|c|c|c|c|}
\hline \multirow[b]{3}{*}{ Characteristic } & \multicolumn{12}{|c|}{ BMI categories } & \multirow[b]{3}{*}{$P^{*}$} \\
\hline & \multicolumn{2}{|c|}{$\begin{array}{l}<18.50 \mathrm{~kg} / \mathrm{m}^{2} \\
(n 232)\end{array}$} & \multicolumn{2}{|c|}{$\begin{array}{c}18.50-24.99 \mathrm{~kg} / \mathrm{m}^{2} \\
(n 2775)\end{array}$} & \multicolumn{2}{|c|}{$\begin{array}{c}25.00-29.99 \mathrm{~kg} / \mathrm{m}^{2} \\
(n 1940)\end{array}$} & \multicolumn{2}{|c|}{$\begin{array}{c}30.00-34.99 \mathrm{~kg} / \mathrm{m}^{2} \\
(n 1008)\end{array}$} & \multicolumn{2}{|c|}{$\begin{array}{c}35.00-39.99 \mathrm{~kg} / \mathrm{m}^{2} \\
(n 364)\end{array}$} & \multicolumn{2}{|c|}{$\begin{array}{c}\geq 40.00 \mathrm{~kg} / \mathrm{m}^{2} \\
(n 134)\end{array}$} & \\
\hline & $\%$ or Mean & $\begin{array}{l}95 \% \mathrm{Cl}, \mathrm{SD} \\
\quad \text { or SE }\end{array}$ & $\%$ or Mean & $\begin{array}{l}95 \% \mathrm{Cl}, \mathrm{SD} \\
\quad \text { or SE }\end{array}$ & $\%$ or Mean & $\begin{array}{l}95 \% \mathrm{Cl}, \mathrm{SD} \\
\quad \text { or SE }\end{array}$ & $\%$ or Mean & $\begin{array}{l}95 \% \mathrm{Cl}, \mathrm{SD} \\
\quad \text { or SE }\end{array}$ & $\%$ or Mean & $\begin{array}{l}95 \% \mathrm{Cl}, \mathrm{SD} \\
\quad \text { or SE }\end{array}$ & $\%$ or Mean & $\begin{array}{l}95 \% \mathrm{Cl}, \mathrm{SD} \\
\quad \text { or SE }\end{array}$ & \\
\hline$\%$ in BMl category and $95 \% \mathrm{Cl}$ & $3 \cdot 3$ & $2 \cdot 9,3 \cdot 8$ & $40 \cdot 9$ & $39 \cdot 8,42 \cdot 1$ & $31 \cdot 1$ & $30 \cdot 0,32 \cdot 2$ & $16 \cdot 5$ & $15 \cdot 6,17 \cdot 4$ & 5.9 & $5 \cdot 4,6.5$ & $2 \cdot 2$ & $1 \cdot 8,2.5$ & $<0.001$ \\
\hline Age (years), mean and SD & 37.68 & $19 \cdot 18$ & $43 \cdot 20$ & $16 \cdot 68$ & $54 \cdot 18$ & $15 \cdot 85$ & $57 \cdot 60$ & 13.97 & 57.05 & 13.97 & $55 \cdot 80$ & $13 \cdot 58$ & $<0.001$ \\
\hline Height $(\mathrm{cm})$, mean and SE & $163 \cdot 2$ & 0.449 & 163.9 & 0.131 & 163.1 & 0.148 & 161.9 & 0.204 & 160.5 & 0.336 & $158 \cdot 7$ & 0.552 & $<0.001$ \\
\hline Weight $(\mathrm{kg})$, mean and SE & $46 \cdot 7$ & 0.479 & $59 \cdot 6$ & 0.141 & $72 \cdot 8$ & 0.158 & 83.84 & 0.218 & $95 \cdot 0$ & 0.359 & $108 \cdot 0$ & 0.590 & $<0.001$ \\
\hline $\begin{array}{l}\text { WC (cm), mean and SE } \\
\text { WC group, } \% \text { and } 95 \% \mathrm{Cl}\end{array}$ & 71.4 & 0.585 & $80 \cdot 0$ & 0.171 & 91.9 & 0.192 & $100 \cdot 9$ & 0.265 & $110 \cdot 8$ & 0.439 & $120 \cdot 7$ & 0.722 & $\begin{array}{l}<0.001 \\
<0.001\end{array}$ \\
\hline$\leq 80 \mathrm{~cm}$ & 9.8 & $9 \cdot 0,10 \cdot 6$ & $79 \cdot 3$ & $77 \cdot 6,81 \cdot 1$ & 9.3 & $7 \cdot 3,11 \cdot 3$ & 1.5 & $0 \cdot 0,3 \cdot 1$ & 0.1 & $0.0,1 \cdot 2$ & 0.1 & $0.0,0.6$ & \\
\hline $80 \cdot 1-87.9 \mathrm{~cm}$ & 0.8 & $0.0,1.7$ & $56 \cdot 3$ & $54 \cdot 3,58 \cdot 4$ & $39 \cdot 3$ & $36 \cdot 9,41 \cdot 7$ & 3.5 & $1 \cdot 6,5 \cdot 3$ & 0.1 & $0.0,1 \cdot 3$ & 0.0 & $0.0,0.0$ & \\
\hline$\geq 88 \mathrm{~cm}$ & 0.5 & $0.0,1 \cdot 1$ & $12 \cdot 2$ & $10 \cdot 8,13.5$ & $40 \cdot 9$ & $39 \cdot 3,42 \cdot 4$ & 30.5 & $29 \cdot 3,31 \cdot 7$ & 11.6 & $10 \cdot 7,12 \cdot 4$ & 4.4 & $3.9,4.9$ & \\
\hline $\begin{array}{l}\text { WHtR, mean and SE } \\
\text { WHtR group, } \% \text { and } 95 \% \mathrm{Cl}\end{array}$ & 0.44 & 0.004 & 0.49 & 0.001 & 0.56 & 0.001 & 0.62 & 0.002 & 0.69 & 0.003 & $0 \cdot 76$ & 0.004 & $\begin{array}{l}<0.001 \\
<0.001\end{array}$ \\
\hline$\leq 0.40$ & $30 \cdot 6$ & $28 \cdot 5,32 \cdot 7$ & $67 \cdot 7$ & $63 \cdot 0,72 \cdot 5$ & $3 \cdot 6$ & $0.0,8.9$ & 0.3 & $0.0,4.5$ & 0.0 & $0.0,1.3$ & 0.0 & $0.0,1.0$ & \\
\hline $0.41-0.50$ & $6 \cdot 3$ & $5 \cdot 5,7 \cdot 1$ & 81.5 & $79 \cdot 7,83 \cdot 3$ & $13 \cdot 2$ & $11 \cdot 2,15 \cdot 2$ & 0.2 & $0.0,1.8$ & 0.0 & $0.0,2.0$ & 0.5 & $0.0,1.0$ & \\
\hline $0.51-0.60$ & 0.7 & $0.0,1.4$ & 34.8 & $33 \cdot 2,36 \cdot 3$ & $51 \cdot 6$ & $49 \cdot 9,53 \cdot 3$ & $12 \cdot 3$ & $11 \cdot 0,13 \cdot 7$ & 0.5 & $0.0,1.4$ & 0.1 & $0.0,0.7$ & \\
\hline$\geq 0.61$ & 0.0 & $0.0,0.8$ & 4.0 & $2 \cdot 2,5 \cdot 8$ & 28.4 & $26 \cdot 4,30 \cdot 4$ & $40 \cdot 0$ & $38.5,41.6$ & 19.9 & $18 \cdot 9,20 \cdot 9$ & $7 \cdot 6$ & $7 \cdot 0,8 \cdot 3$ & \\
\hline
\end{tabular}

WC, waist circumference; WHtR, waist-to-height ratio

${ }^{*}$ According to the $x^{2}$ test or ANOVA/ANCOVA where appropriate. 
(a)

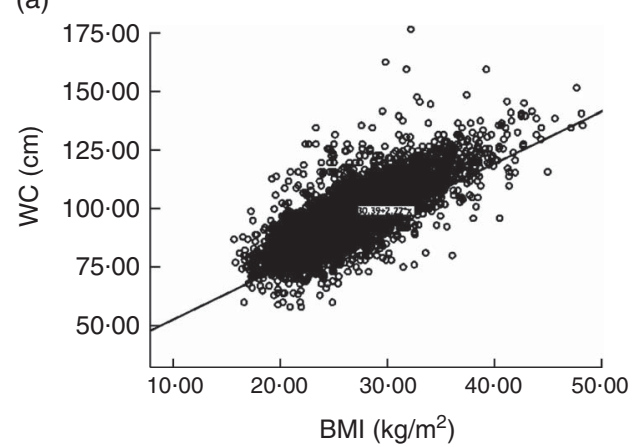

(c)

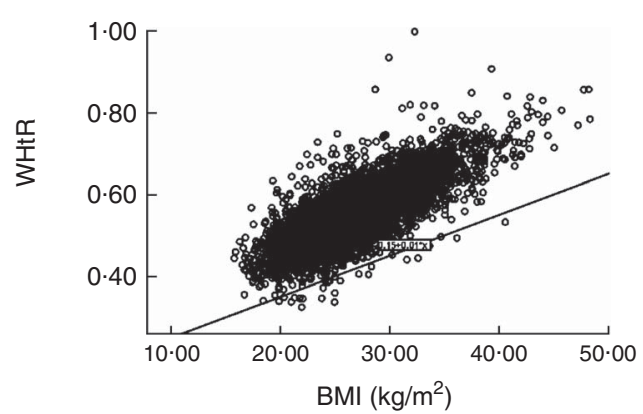

(e)

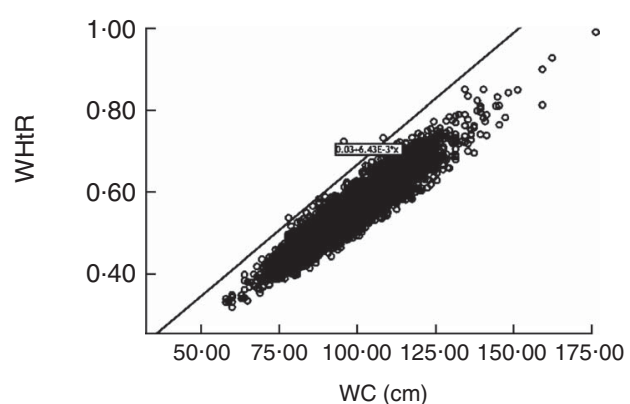

(b)

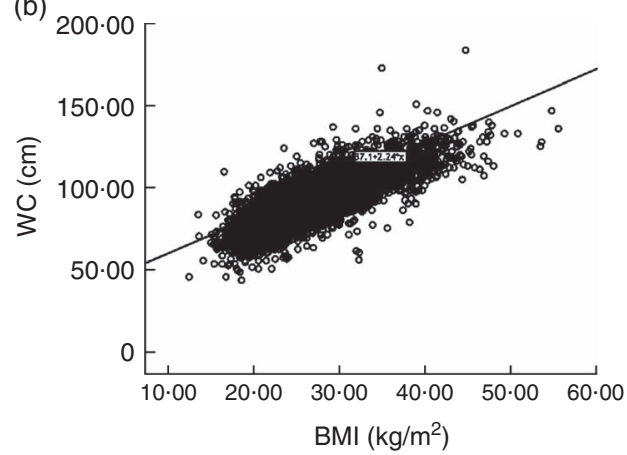

(d)

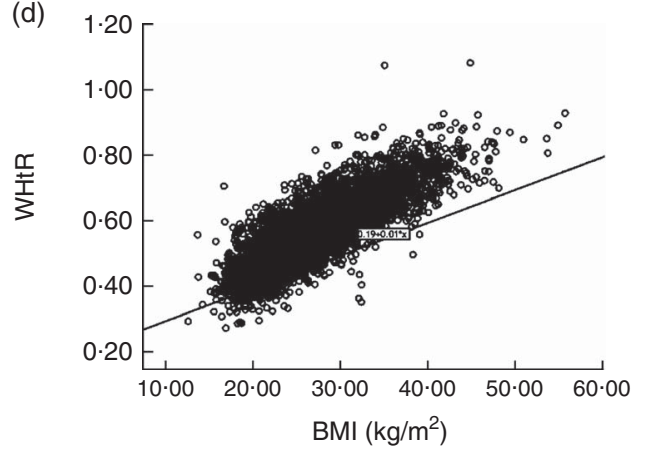

(f)

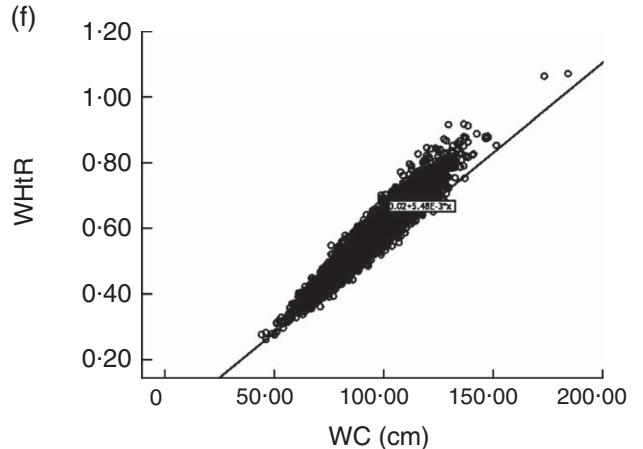

Fig. 1 Correlation between BMI, waist circumference (WC) and waist-to-height ratio (WHtR), by sex, among adults ( $n 12460)$ aged $\geq 20$ years, Republic of Serbia, 2013: (a) WC $v$. BMI in men $\left(R^{2}=0.688, y=30.39+2.22 x\right)$; (b) WC $v$. BMl in women $\left(R^{2}=0.605\right.$, $y=37.10+2.24 x)$; (c) WHtR $v$. BMI in men $\left(R^{2}=0.709, y=0.15+0.01 x\right)$; (d) WHtR $v$. BMI in women $\left(R^{2}=0.617, y=0.19+0.01 x\right)$; (e) WHtR $v$. WC in men $\left(R^{2}=0.933, y=0.03+6.43 \times 10^{-3} x\right)$; (f) WHtR $v$. WC in women $\left(R^{2}=0.877, y=0.02+5.48 \times 10^{-3} x\right)$

between 80.0 and $87.9 \mathrm{~cm}$, and $42 \%$ had $\mathrm{WC} \geq 88 \mathrm{~cm}^{(31)}$. Among males, 23.9\% had WC between 94 and $101.9 \mathrm{~cm}$, and $22 \cdot 2 \%$ had $\mathrm{WC} \geq 102 \mathrm{~cm}^{(31)}$. Normal-weight men and women with increased WC values are of particular interest due to increased associated health risks of cardiometabolic abnormalities. However, within each BMI category men and women with high WC values are at greater health risk than those with normal WC values ${ }^{(29)}$, so the former are in need of health education ${ }^{(32)}$.

In our population, among those who were overweight and obese according to WHtR, $27.4 \%$ and $1.0 \%$ of men respectively and $34.8 \%$ and $4.0 \%$ of women respectively were in the group with normal BMI. At the same time, $20.4 \%$ of men and $13.2 \%$ of women with WHtR of $0 \cdot 41-0.50$ were overweight according to BMI. The study by Andreenko et al. showed that both men and women with normal weight according to BMI values also had normal WHtR values ${ }^{(32)}$. In the present study $77.0 \%$ of men and $81.5 \%$ of women with WHtR values of $0.41-0.50$ had normal BMI. Ashwell and Gibson showed that $30 \%$ of men with normal weight according to BMI had WHtR $>0.5$, while this was the case in $26 \%$ of normal-weight women according to $\mathrm{BMI}^{(33)}$. However, according to the same authors one in ten of the total population and more than $25 \%$ of the normal-weight population according to BMI value had WHtR $>0.5$ and are at risk due to having central fat distribution ${ }^{(33)}$. Data from a number of studies have demonstrated that WHtR is superior in identifying cardiometabolic abnormalities to $\mathrm{BMI}^{(22,23,32,33)}$. A Korean study showed that WHtR has the best predictive value for evaluating the metabolic risk factors compared with BMI or WC alone among individuals with normal $\mathrm{BMI}$ and $\mathrm{WC}^{(34)}$. 
(a)

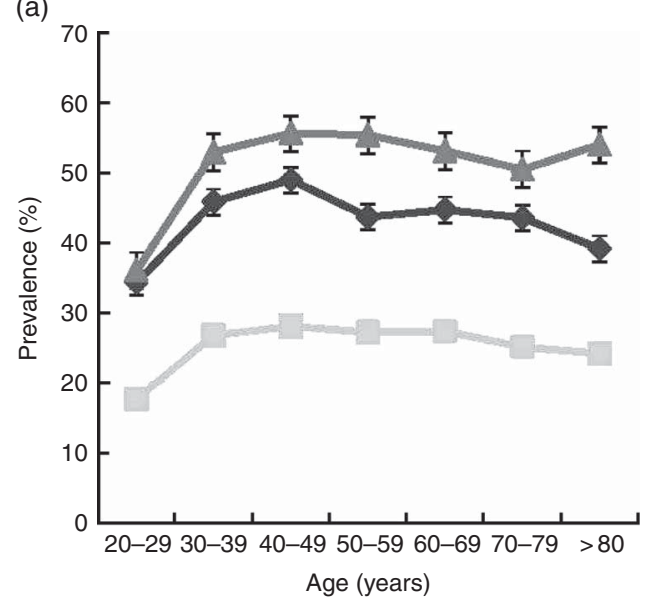

(c)

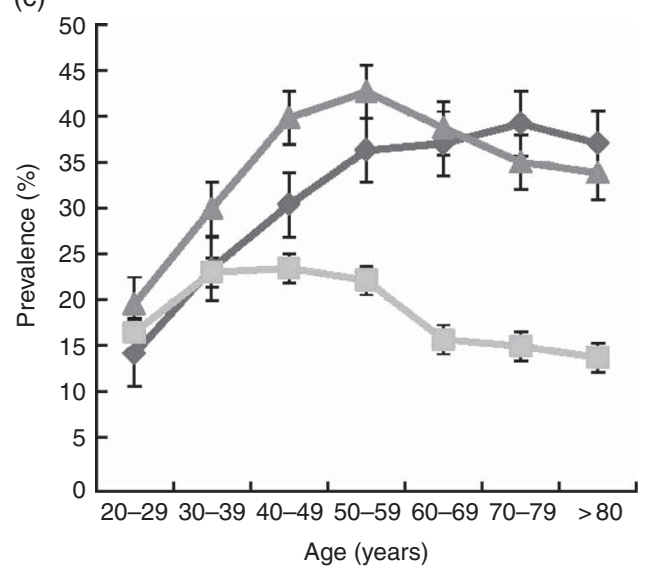

(b)

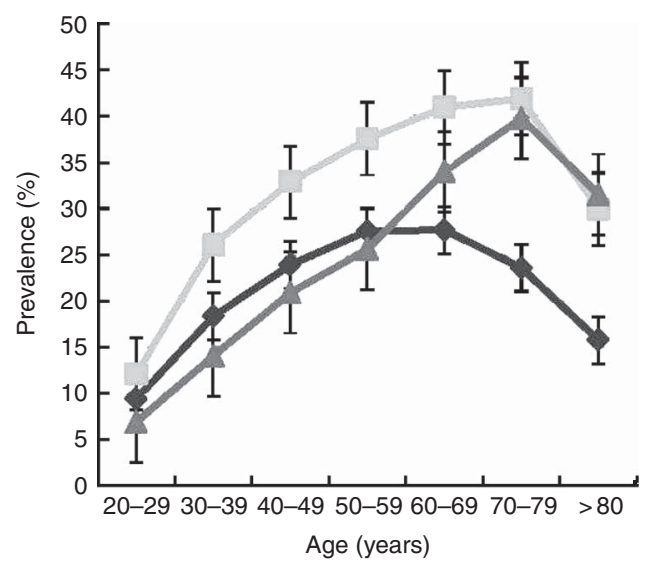

(d)

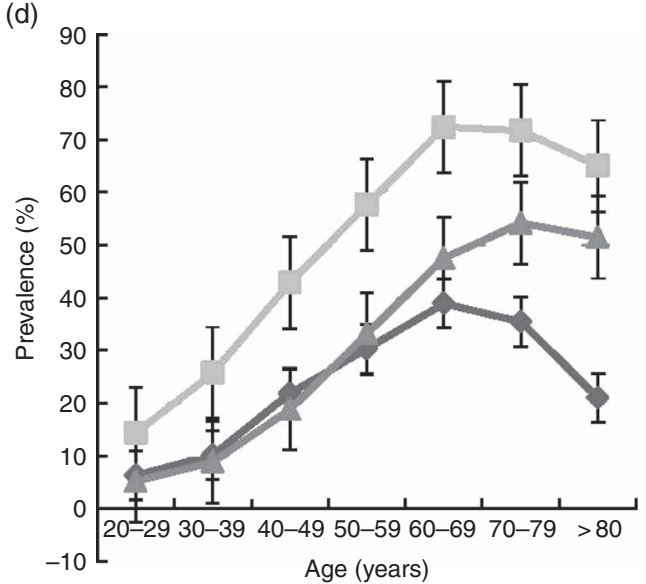

Fig. 2 Age-specific prevalence of overweight and obesity according to criteria based on BMI ( $\diamond$ ), waist circumference (WC; $\square$ ) and waist-to-height ratio (WHtR; $\Delta$ ), by sex, among adults $(n 12460)$ aged $\geq 20$ years, Republic of Serbia, 2013: (a) overweight prevalence among men; (b) obesity prevalence among men; (c) overweight prevalence among women; (d) obesity prevalence among women. Values are means with their standard errors indicated by vertical bars

The strength of our study is its representative sample with a high number of participants, as well as the fact that data were not self-reported but were obtained by measurements of body weight, height and WC. The main limitation of the study is that we used only one cut-off for WC, although it is known that it depends on some population characteristics and cannot be universal ${ }^{(16)}$. In addition, overweight and obesity assessed by the three different measures were not related to the diseases for which they are considered to be the risk factors. Furthermore, the study did not include persons who lived in collective households and/or institutions, residents of Kosovo and Metohia region (under the UN Mission) and persons who were mentally unable to participate in the survey.

\section{Conclusion}

In the present study discrepancies between BMI, WC and WHtR in the assessment of overweight and obesity were found. Which of these anthropometric measures should be used, or whether two or all three of them should be applied, depends on their associations with cardiovascular or some other disease of interest.

\section{Acknowledgements}

Financial support: This research received no specific grant from any funding agency in the public, commercial or notfor-profit sectors. The authors declare that this research received no support in financial or other manner. Conflict of interest: The authors declare that they have no competing interests. Authorship: M.Ž.M. and J.M.G.R. designed and conducted the research. M.Ž.M., J.M.G.R. and J.M.M. analysed data. J.M.G.R. and H.D.V. wrote the paper. N.D.V., M.I.N. and J.M.M. provided feedback on the paper. M.Ž.M., J.M.G.R., H.D.V. and J.M.M. had primary responsibility for the final content. All authors have read and approved the final manuscript. Ethics of human 
subject participation: The study was approved by the ethical review boards of all participating institutions: Institute of Public Health of Serbia and Faculty of Medicine, University of Belgrade. All respondents were informed about the purpose of the study and gave written consent to participate.

\section{References}

1. World Health Organization (2013) Methodology and summary. Country profiles on nutrition, physical activity and obesity in the 53 WHO European Region Member States. http://www.euro.who.int/en/publications/abstracts/countryprofiles-on-nutrition,-physical-activity-and-obesity-in-the53-who-european-region-member-states.-methodology-andsummary-2013 (accessed January 2016).

2. Ministry of Health of the Republic of Serbia \& Institute of Public Health of Serbia 'Dr Milan Jovanović Batut' (2014) National Health Survey 2013 - Key findings. http://www.batut.org.rs/download/publikacije/2013Serbia HealthSurvey.pdf (accessed December 2015).

3. Wyatt SB, Winters KP \& Dubbert PM (2006) Overweight and obesity: prevalence, consequences and causes of a growing public health problem. Am J Med Sci 331, 166-174.

4. James WPT, Jackson-Leach R, Mhurchu CN et al. (2004) Overweight and obesity (high body mass index). In Comparative Quantification of Health Risks: Global and Regional Burden of Disease Attributable to Selected Major Risk Factors, pp. 497-596 [M Ezzati, AD Lopez, A Rodgers et al., editors]. Geneva: WHO.

5. Atanaskovic-Markovic Z, Bjegovic V, Jankovic S et al. (2003) The burden of disease and injury in Serbia. http://apps.who. int/fctc/implementation/database/sites/implementation/files/ documents/reports/R_Serbia_annex6_burden_of_disease_ study_2003.pdf (accessed February 2016).

6. Heymsfeld SB, Scherzer R, Pietrobelli A et al. (2009) Body mass index as a phenotypic expression of adiposity: quantitative contribution of muscularity in a populationbased sample. Int J Obes (Lond) 33, 1363-1373.

7. Gomez-Ambrosi J, Silva C, Galofre JC et al. (2012) Body mass index classification misses subjects with increased cardiometabolic risk factors related to elevated adiposity. Int J Obes (Lond) 36, 286-294.

8. Heo M, Faith MS, Pietrobelli A et al. (2012) Percentage of body fat cut-offs by sex, age and race-ethnicity in the US adult population from NHAHES 1999-2004. Am J Clin Nutr 95, 594-602.

9. Ashwell M (2011) Charts based on body mass index and waist-to-height ratio to assess the health risks of obesity: a review. Open Obes J 3, 78-84.

10. Lee CM, Huxley RR, Wildman RP et al. (2008) Indices of abdominal obesity are better discriminators of cardiovascular risk factors than BMI: a meta-analysis. J Clin Epidemiol 61, 646-653.

11. Ashwell M, Gunn P \& Gibson S (2012) Waist-to-height ratio is a better screening tool than waist circumference and BMI for adult cardiometabolic risk factors: systematic review and meta-analysis. Obes Rev 13, 275-286.

12. World Health Organization (2011) Waist Circumference and Waist-Hip Ratio. Report of a WHO Expert Consultation, Geneva, 8-11 December 2008. Geneva: WHO.

13. Zhu S, Wang Z, Heshka S et al. (2002) Waist circumference and obesity-associated risk factors among whites in the third National Health and Nutrition Examination Survey: clinical action thresholds. Am J Clin Nutr 76, 743-749.

14. Jansen I, Katzmarzyk PT \& Ross R (2002) Body mass index, waist circumference and health risk: evidence in support of current National Institutes of Health Guidelines. Arch Intern Med 162, 2074-2079.

15. Arden CI, Katzmarzyk PT, Jansen I et al. (2003) Discrimination of health risk by combined body mass index and waist circumference. Obes Res 11, 135-142.

16. Browning L, Hsieh S \& Ashwell M (2010) A systematic review of waist-to-height ratio as screening tool for the prediction of cardiovascular disease and diabetes: 0.5 could be a suitable global boundary value. Nutr Res Rev $\mathbf{2 3}$, $247-269$.

17. Srinivasan SR, Wang R, Chen W et al. (2009) Utility of waistto-height ratio in detecting central obesity and related adverse cardiovascular risk profile among normal weight younger adults from the Bogalusa Heart Study. Am J Cardiol 104, 721-724.

18. Li WC, Chen IC, Chang YC et al. (2013) Waist-to-height ratio, waist circumference and body mass index as indices of cardiometabolic risk among 36,642 Taiwanese adults. Eur J Nutr 52, 57-65.

19. European Commission, EUROSTAT Working Group on Public Health Statistics (2013) European Health Interview Survey - EHIS wave 2, Methodological manual. http://ec. europa.eu/eurostat/documents/3859598/5926729/KS-RA13-018-EN.PDF/26c7ea80-01d8-420e-bdc6-e9d5f6578e7c (accessed January 2016).

20. European Commission, EUROSTAT Working Group on Public Health Statistics (2006) European Health Interview Survey (EHIS) questionnaire. http://ec.europa.eu/health/ ph_information/implement/wp/systems/docs/ev_20070315_ ehis_en.pdf (accessed January 2016).

21. World Health Organization (2000) Obesity: Preventing and Managing the Global Epidemic. Report of a WHO Consultation on Obesity. WHO Technical Report Series no. 894, pp. 5-37. Geneva: WHO.

22. Lean ME, Han TS \& Morrison CE (1995) Waist circumference as a measure for indicating need for weight management. BMJ 311, 158-161.

23. Ashwell M \& Hsieh SD (2005) Six reasons why the waist-toheight ratio is a rapid and effective global indicator for health risks of obesity and how its use could simplify the international public health message on obesity. Int J Food Sci Nutr 56, 303-307.

24. Krakauer NY \& Krakauer JC (2012) A new body shape index predicts mortality hazard independently of body mass index. PLoS One 7, e 39504.

25. Kyle UG, Genton L, Hans D et al. (2001) Total body mass, fat mass, fat-free mass, and skeletal muscle in older people: cross-sectional differences in 60-year-old persons. $\mathrm{J} \mathrm{Am}$ Geriatr Soc 49, 1633-1640.

26. Song X, Jousilahti P, Stehouwer CDA et al. (2013) Comparison of various surrogate obesity indicators as predictors of cardiovascular mortality in four European populations. Eur J Clin Nutr 67, 1298-1302.

27. Kamadjeu RM, Edwards R, Atanga JS et al. (2006) Anthropometry measures and prevalence of obesity in the urban adult population of Cameroon: an update from the Cameroon

Burden of Diabetes Baseline Survey. BMC Public Health 6, 228.

28. Chinedu SN, Ogunlana OO, Azuh DE et al. (2013) Correlation between body mass index and waist circumference in Nigerian adults: implication as indicators of health status. $J$ Public Health Res 2, e16.

29. Fu S, Luo L, Ye P et al. (2014) The abilities of new anthropometric indices in identifying cardiometabolic abnormalities, and influence of residence area and lifestyle on these anthropometric indices in a Chinese community-dwelling population. Clin Interv Ageing 9, 179-189.

30. Krakauer NY \& Krakauer JC (2014) Expansion of waist circumference in medical literature: potential clinical application of a body shape index. J Obes Weight Loss Ther $\mathbf{4}, 216$. 
31. Rezende F, Rosado L, Ribeiro R et al. (2006) Body mass index and waist circumference: association with cardiovascular risk factors. Arq Bras Cardiol 87, 728-734.

32. Andreenko E, Mladenova S \& Akabaliev V (2015) Anthropometric obesity indices in relation to age, educational level, occupation and physical activity in Bulgarian men. Nutr Hosp 31, 658-665.
33. Ashwell M \& Gibson S (2014) A proposal for a primary screening tool: 'keep your waist circumference to less than half your height'. BMC Med 12, 207.

34. Park YS \& Kim JS (2012) Association between waist-toheight ratio and metabolic risk factors in Korean adults with normal body mass index and waist circumference. Tohoku J Exp Med 228, 1-8. 